\title{
On the Aromaticity and Acidity of 1-Hydroxy-4,5-benzotropylium Derivatives
}

Takuya Kodama, ${ }^{\text {ab }}$ Yuki Kawashima, ${ }^{a}$ Zhirong Deng, ${ }^{a}$ and Mamoru Tobisu*a,b

${ }^{a}$ Department of Applied Chemistry, Graduate School of Engineering, Osaka University, Suita, Osaka 565-0871, Japan.

${ }^{b}$ Innovative Catalysis Science Division, Institute for Open and Transdisciplinary Research Initiatives (OTRI), Osaka University, Suita, Osaka 565-0871, Japan.

\section{Abstract}

The aromaticity of 1-hydroxy-4,5-benzotropylium was assessed based on experimental and theoretical investigations. An X-ray crystallographic analysis revealed a decrease of bond alternation in the seven-membered ring of 1-hydroxy-4,5-benzotropylium derivatives compared with that of the parent 4,5-benzotropones, which is indicative of an increase in aromaticity upon protonation. NICS and AICD calculation also supported the increased aromaticity of 1-
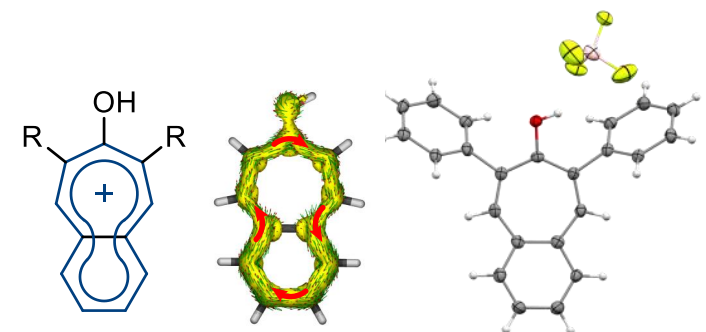

$\mathrm{R}=$ Aryl, Alkyl, Ester

-X-Ray Structures $\bullet$ NICS/AICD Calculations $\bullet \mathrm{pK}_{\mathrm{a}}$ Determination hydroxy-4,5-benzotropylium. The $\mathrm{p} K_{\mathrm{a}}$ values for a series of 1-hydroxy-4,5-benzotropylium derivatives were also determined.

Since the first synthesis of cyclohexa-2,4,6-trienone, or tropone (1) in the early 1950s, ${ }^{1,2}$, it has been considered to be a representative scaffold of non-benzenoid aromatic compounds ${ }^{3,4}$ because the $6 \pi$ aromaticity is expected when the contribution of the polar canonical structure 1B is significant (Chart 1). Although computational studies suggested that $\mathbf{1}$ possesses some degree of aromatic character derived from $\mathbf{1 B},{ }^{5}$ the physical properties of $\mathbf{1}$, including the dipole moment,${ }^{6 a, 6 \mathrm{c}}$ the ${ }^{1} \mathrm{H}$ NMR chemical shifts of the compound, ${ }^{6 \mathrm{~b}}$ the $\mathrm{C}=\mathrm{O}$ stretching frequency in IR spectra, ${ }^{6 \mathrm{~d}}$ and the fact that it reacts ${ }^{4 \mathrm{a}-4 \mathrm{e}, 4 \mathrm{~g}, 4 \mathrm{~h}, 4 \mathrm{j}}$ as a polyenoic compound rather than an aromatic compound all indicate that the contribution of $\mathbf{1 B}$ to the characteristics of the compound is insignificant. Nucleus-independent chemical shift $(\mathrm{NICS})^{7}$ calculations also indicate that the degree aromaticity of $\mathbf{1}$ is not quite strong (NICS(0) : 1.3) ${ }^{8}$ In contrast, the corresponding conjugate acid of $\mathbf{1}$, hydroxytropylium $\mathbf{2},{ }^{1 \mathrm{a}, 2,9}$ which is generated by the protonation of $\mathbf{1}$, shows increased aromatic properties, which is supported by NMR data ${ }^{10 \mathrm{a}}$ and NICS calculations (NICS(0) : -5.3). ${ }^{10 \mathrm{~b}}$ The crystal structure of $2(\mathrm{X}=\mathrm{Cl})$ was recently reported by the Pöthig group ${ }^{11}$ which displayed a planer geometry with $\mathrm{C}-\mathrm{C}$ bonds alternation of the seven-membered ring. These results indicate that the protonated form of tropone $\mathbf{2 A}$ and hydroxytropylium $2 \mathrm{~B}$ both contribute to the characteristics of the molecule.

The structure, electronic properties, reactivities, and metal coordination mode of troponoid compounds, as represented by tropone and tropolone, markedly vary by the annulation of extra fused aromatic rings. ${ }^{4 \mathrm{~g}, 4 \mathrm{j}, 12-14}$ In addition to the effect of annulation, the introduction of substituents at the 2,7-positions of 4,5-benzotropone also affects the dipole moment ${ }^{12 \mathrm{~d}, 12 \mathrm{i}}$ or $\mathrm{C} 1-\mathrm{C} 2$ and $\mathrm{C} 1-\mathrm{C} 7$ single bond lengths of the molecule. ${ }^{13 \mathrm{~g}, 13 \mathrm{i}}$ Although numerous fused tropone derivatives have been synthesized over the past 100 years, ${ }_{4,4 j}$ the effect of annulation on the aromaticity of the corresponding conjugate acid ${ }^{12 b, 12 f, 12 k, 13 \mathrm{~d}, 13 \mathrm{~h}, 13 \mathrm{j}}($ i.e., 4 ) has not been investigated thus far, to the 
best of our knowledge. Here, we report on the protonation of some 4,5-benzotropone derivatives 3 and the characterization 1-hydroxy-4,5-benzotropylium derivatives 4 by NMR measurements, X-ray crystallographic analysis and computational methods.

Chart 1. Schematic Representation of Protonation of Tropone

(a) Tropone (1)

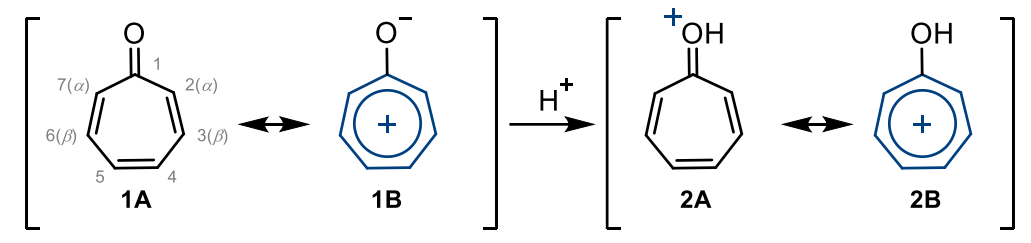

(b) 4,5-Benzotropone (This work)

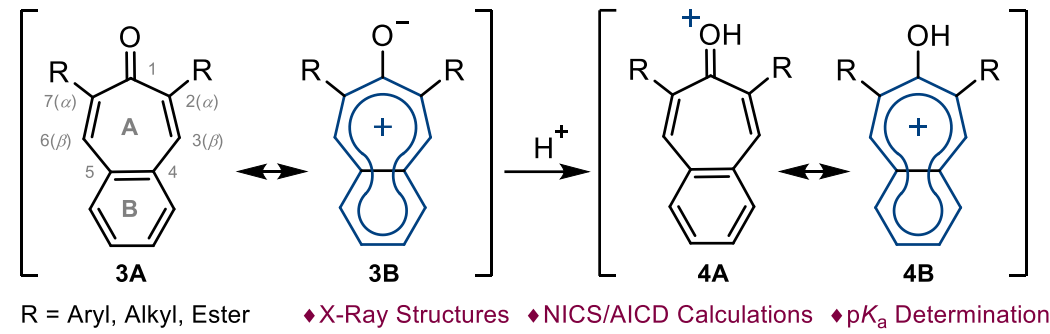

To investigate the effect of substituents on 4,5-benzotropyrium derivatives, we focused on the synthesis of a series of 2,7-disubstituted-4,5-benzotropones, including those bearing aryl (3a, 3d) alkyl (3b, 3e) and ester (3c, 3f) groups. The 4,5-benzotropones 3a-3f were synthesized by the Knoevenagel condensation of $o$-phthalaldehyde and the corresponding ketones in the presence of a suitable base ( $\mathrm{NaOH}$ for $\mathbf{3 a}, \mathbf{3 d}$; piperidine for $\mathbf{3 b}, \mathbf{3 e} ; \mathrm{NaOEt}$ for $\mathbf{3 c}, \mathbf{3 f})$ (Scheme S1). ${ }^{15}$ Treatment of $\mathbf{3}$ with two equivalents of $\mathrm{HBF}_{4} \cdot \mathrm{Et}_{2} \mathrm{O}$ in $\mathrm{CH}_{2} \mathrm{Cl}_{2}$ at room temperature successfully afforded good yields of the corresponding 1-hydroxy-4,5-benzohydroxytropylium derivatives $\mathbf{4 a}, \mathbf{4 b}$ and $\mathbf{4 c}$ as $\mathrm{BF}_{4}$ salts (Scheme 1).

Scheme 1. Synthesis of 1-Hydroxy-4,5-benzotropyriums $4 .^{a}$<smiles>[R]c1cc2ccccc2cc([R])c1=O</smiles>

3a $(\mathrm{R}=\mathrm{Ph})$

$3 \mathbf{b}(\mathrm{R}=\mathrm{Me})$

$3 \mathrm{c}\left(\mathrm{R}=\mathrm{CO}_{2} \mathrm{Me}\right)$ (a)

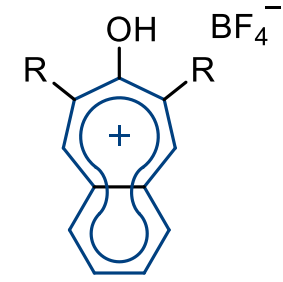

$\begin{array}{lr}\text { 4a }(\mathrm{R}=\mathrm{Ph}) & 95 \% \\ \text { 4b }(\mathrm{R}=\mathrm{Me}) & 81 \% \\ \text { 4c }\left(\mathrm{R}=\mathrm{CO}_{2} \mathrm{Me}\right) & 81 \%\end{array}$

${ }^{a} 3(1.0 \mathrm{mmol}), \mathrm{HBF}_{4} \cdot \mathrm{Et}_{2} \mathrm{O}(2.0 \mathrm{mmol})$ in $\mathrm{CH}_{2} \mathrm{Cl}_{2}$ at $\mathrm{rt}$ for $15 \mathrm{~min}$.

1-Hydroxy-4,5-benzohydroxytropylium $\mathbf{4 a}, \mathbf{4 b}$ and $\mathbf{4 c}$ could be crystalized from $\mathrm{CH}_{2} \mathrm{Cl}_{2}$ to form pale yellow crystals that were suitable for X-ray crystallographic analysis. The ORTEP drawings of $\mathbf{4 a}, \mathbf{4 b}$ and $\mathbf{4 c}$ are shown in Figure 1 and the structural parameters are summarized in Table 1. The molecular structures of $\mathbf{4 a}$ and $\mathbf{4 c}$ were slightly distorted, and the $\mathrm{C} 2$ and $\mathrm{C} 7$ carbons of $\mathbf{4 a} \mathbf{a} \mathbf{4} \mathbf{c}$ deviated from the mean plane of the 4,5-benzotropylium ring by 
0.016/0.163 and 0.088/0.147 $\AA$, respectively, which is in sharp contrast to the higher planarity displayed by $\mathbf{4 b}$. This difference can be attributed to the bulkiness of the $\mathrm{C} 2$ and $\mathrm{C} 7$ substituents (i.e., $\mathrm{Ph}$ and $\mathrm{CO}_{2} \mathrm{Me}$ ). The $\mathrm{C} 1-\mathrm{O}$ bond lengths of $4 \mathbf{a}(1.33 \AA), \mathbf{4 b}(1.32 \AA)$ and $4 \mathbf{c}(1.31 \AA)$ were elongated compared with those of the parent tropones $3 \mathbf{a}$ $(1.22 \AA),{ }^{13 g, 13 i} \mathbf{3 b}\left(1.24 \AA\right.$ ), and $\mathbf{3} \mathbf{c}^{14}(1.22 \AA$ ) (Table 1, Figure S5 and S6). The distance for the C2-C3/C6-C7 bonds in 4 were also elongated while the $\mathrm{C} 1-\mathrm{C} 2 / \mathrm{C} 7-\mathrm{C} 1$ and $\mathrm{C} 3-\mathrm{C} 4 / \mathrm{C} 5-\mathrm{C} 6$ bond lengths were shorter compared with those of $\mathbf{3 a},{ }^{13 \mathrm{~g}, 13 \mathrm{i}} \mathbf{3 b}$, and $\mathbf{3 c}{ }^{14}$ The bond alternations for the seven-membered ring (ring A) of the 1-hydroxy-4,5benzotropylium derivatives became smaller compared to those of the parent 4,5-benzotropone derivatives, while the bond alternations for the fused benzene ring (ring B) became slightly larger upon protonation. To further evaluate the aromaticity of $\mathbf{3}$ and $\mathbf{4}$ in more detail, harmonic oscillator model for aromaticity (HOMA) ${ }^{16}$ values were calculated for both the seven-membered ring (ring A) and the fused benzene ring (ring B) of $\mathbf{3 a}-\mathbf{3 c}, \mathbf{4 a}-\mathbf{4 c}$. The HOMA values for ring A of $\mathbf{4 a}(0.809), \mathbf{4 b}(0.681)$, and $\mathbf{4 c}(0.678)$ were larger compared to those of $\mathbf{3 a} \mathbf{a}^{13 \mathrm{~g}, 13 \mathrm{i}}(-0.019)$, 3b $(0.071)$, and $\mathbf{3} \mathbf{c}^{14}(-0.015)$, which are close to zero. Concerning ring B, the HOMA values of $\mathbf{4 a}-\mathbf{4 c}$ were decreased slightly compared to those of $\mathbf{3 a}-\mathbf{3 c}$ but still remained high. These results indicate that the polar resonance form 4B (Chart 1) is the dominant contributor to the structures of 1-hydroxy-4,5-benzotropylium derivatives whereas $\mathbf{3 A}$ is more dominant contribution for the 4,5-benzotrones derivatives. The aromaticity of $\mathbf{4}$ was also assessed by DFT calculations. NICS(1) values of 1-hydroxy-4,5-benzotropylium with no substituents [i.e., 4 ( $\mathrm{R}=$

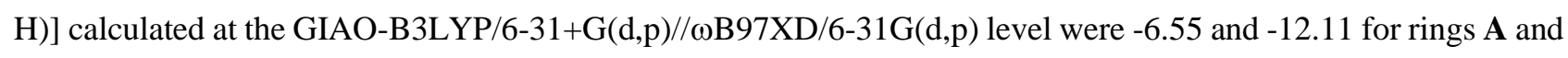
B, respectively. The diatropicity of heptagonal ring A was significantly increased compared to the parent 4,5benzotropone (-1.06), as was reported for the corresponding tropone/hydroxytropylium system. ${ }^{8,10}$ The contribution of 4B was also supported by anisotropy of induced current density (AICD) ${ }^{17}$ calculations, in which a diatropic ring current originating from a $10 \pi$ macrocyclic system was observed (Figure $2 b$ ). In contrast, the AICD plot for $\mathbf{3}$ ( $\mathrm{R}=$ $\mathrm{H}$ ) revealed that a strong diatropic ring current was observed only in the fused benzene ring (ring $\mathrm{B}$ ), while the seven-membered ring possesses a more polyenic character (Figure 2a).

To evaluate the acidity of 1-hydroxy-4,5-benzotropylium derivatives, NMR titration measurements were carried out using more soluble 4,5-benzotropone derivatives 3d-3f. Upon the addition of $0-10$ equivalents of $\mathrm{HBF}_{4} \cdot \mathrm{Et}_{2} \mathrm{O}$ to the 4,5-benzotropone derivatives $\mathbf{3 d}-\mathbf{3 f}$, the resonance of the $\beta$-protons of $\mathbf{3 d}-\mathbf{3 f}$ displayed a down shield-shift. The $\mathrm{p} K_{\mathrm{a}}$ values for the conjugate acids $\mathbf{4 d}, \mathbf{4 e}$, and $\mathbf{4 f}$ were determined by non-linear least squares of a plot of the changes in ${ }^{1} \mathrm{H}$-NMR chemical shifts of $\beta$-protons $\Delta \delta$ as a function of the initial $\mathrm{HBF}_{4}$ concentration to be $1.54,1.70$, and 1.49, respectively (Table 2, Figure S7, and Table S1). The 1-hydroxy-4,5-benzotropylium derivative bearing electron-withdrawing groups at the 2,7-positions were slightly more acidic than the derivative that contained electron-donating groups, which can be attributed to the stability of the generated 1-hydroxy-4,5-benzotropylium. 
(a)

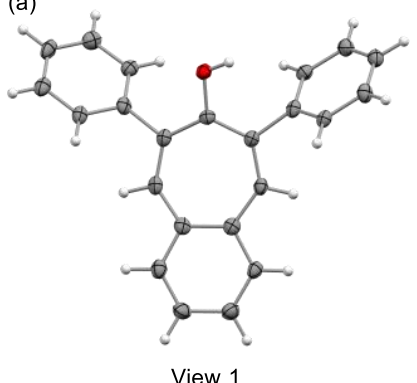

View 1

(b)

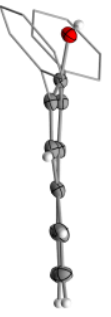

View 2

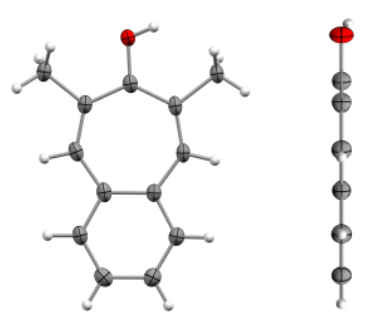

(d)
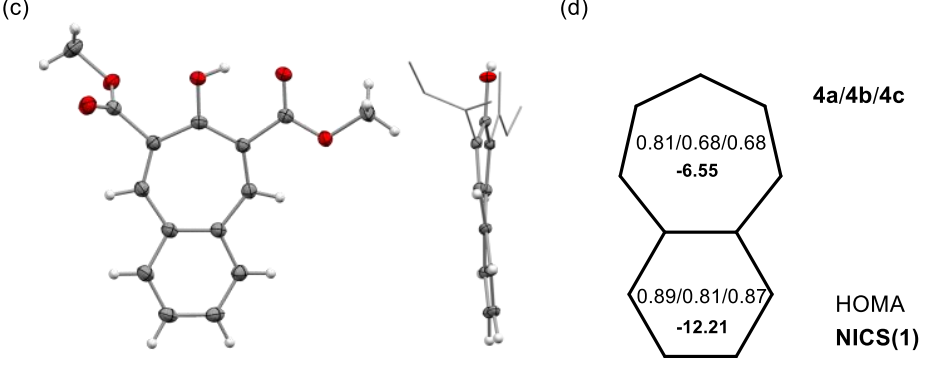

Figure 1. ORTEP drawing of (a) $\mathbf{4 a}$ at the $30 \%$ probability level and (b) $\mathbf{4 b}$ and (c) $\mathbf{4 b}$ at $50 \%$ probability level. $\mathrm{BF}_{4}{ }^{-}$anions were omitted for clarity. Hydrogen atoms of the substituents on the 2,7-positions in View 2 were omitted for the sake of clarity. (d) HOMA values for $\mathbf{4 a}-\mathbf{4 c}$ and NICS(1) values of ring A and B for non-substituted analog of 4.

Table 1. Selected $\mathrm{C}-\mathrm{C}$ and $\mathrm{C}-\mathrm{O}$ bond length/ $\mathrm{A}$ of 4,5-benzotropone scaffold of $\mathbf{3 a}-\mathbf{3 c}$ and $\mathbf{4 a - 4 c}$ and HOMA

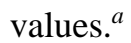

\begin{tabular}{|c|c|c|c|c|c|c|c|}
\hline & \multicolumn{4}{|c|}{ bond length / $\AA$} & \multirow{2}{*}{$\frac{\text { distance / } \AA}{\mathrm{C} 2-\mathrm{m} 1 / \mathrm{C} 7-\mathrm{m} 2}$} & \multicolumn{2}{|c|}{ HOMA } \\
\hline & $\mathrm{O}-\mathrm{C} 1$ & $\mathrm{C} 1-\mathrm{C} 2 / \mathrm{C} 7-\mathrm{C} 1$ & $\mathrm{C} 2-\mathrm{C} 3 / \mathrm{C} 6-\mathrm{C} 7$ & $\mathrm{C} 3-\mathrm{C} 4 / \mathrm{C} 5-\mathrm{C} 6$ & & $\operatorname{ring} \mathbf{A}$ & ring $\mathbf{B}$ \\
\hline 3a & 1.217 & $1.217 / 1.218$ & $1.350 / 1.354$ & $1.448 / 1.447$ & & -0.019 & 0.943 \\
\hline $4 \mathbf{a}$ & $1.327(6)$ & $1.427(8) / 1.423(8)$ & $1.381(8) / 1.389(8)$ & $1.411(8) / 1.412(8)$ & $0.016 / 0.088$ & 0.809 & 0.888 \\
\hline 3b & $1.237(2)$ & $1.447(2) / 1.476(2)$ & $1.355(2) / 1.354(2)$ & $1.443(2) / 1.447(2)$ & & 0.071 & 0.896 \\
\hline $4 b$ & $1.321(6)$ & $1.438(5) / 1.431(5)$ & $1.368(6) / 1.380(2)$ & $1.423(6) / 1.417(6)$ & $0.000 / 0.000$ & 0.681 & 0.812 \\
\hline $3 \mathbf{c}$ & $1.222(2)$ & $1.479(2) / 1.480(2)$ & $1.353(2) / 1.349(2)$ & $1.445(2) / 1.452(2)$ & & -0.015 & 0.927 \\
\hline $4 \mathrm{c}$ & $1.307(2)$ & $1.426(2) / 1.429(2)$ & $1.373(2) / 1.362(2)$ & $1.425(2) / 1.429(2)$ & $0.163 / 0.147$ & 0.678 & 0.869 \\
\hline
\end{tabular}

${ }^{a}$ Structural parameters for 3a (CCDC 1145437) and 3c (CCDC 2036613) were abstracted from the Cambridge Structural Database. $\mathrm{m} 1$ and $\mathrm{m} 2$ are projection points of $\mathrm{C} 2$ and $\mathrm{C} 7$ on the mean plane of a benzotropone scaffold, respectively.
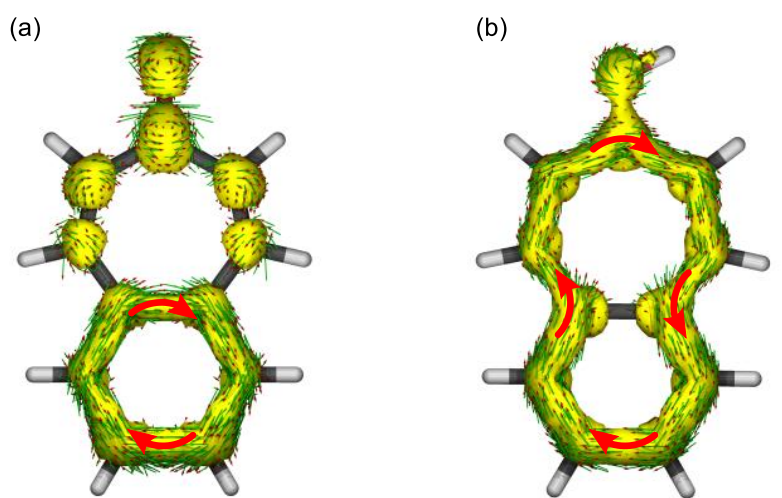

Figure 2. AICD plots of the $\pi$ system of (a) 4,5-benzotropone and (b) 1-hydroxy4,5-benzotropylium. The red arrow denote the induced ring current: clockwise for diatropic (isosurface value 0.05 a. u.). 
Table 2. $\mathrm{p} K_{\mathrm{a}}$ Values of $\mathbf{4 d - 4 f}$ in $\mathrm{CH}_{2} \mathrm{Cl}_{2}$.

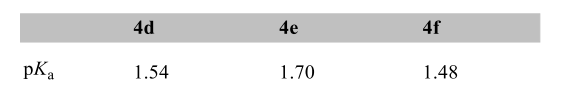

In summary, 1-hydroxy-4,5-benzotropylium derivatives were synthesized and characterized by X-ray crystallographic analysis, NMR measurements and quantum calculations. In contrast to 4,5-benztotropone, in which the fused benzene ring has an explicit local aromatic character, an increase in the HOMA values, the negative NICS(1) values for seven-membered ring, and a ring current in the $10 \pi$ macrocyclic system in the AICD plot indicated that the polar canonical structure, in which the aromaticity of the seven-membered ring is enhanced, is the major contributor to its characteristics. The structure of 1-hydroxy-4,5-benzotropylium was distorted by the presence of bulky substituents at the 2,7-positions. The introduction of substituents at the 2,7-positions affected on $\mathrm{p} K_{\mathrm{a}}$ values of 1-hydroxy-4,5-benzotropylium in which electron-donating groups cause it to be less acidic, whereas electron withdrawing groups cause it to be more acidic.

\section{Supporting Information}

Experimental procedures and supporting characterization data and spectra (PDF)

Compound $3 \mathbf{b}, \mathbf{4 a}, \mathbf{4 b}$, and $\mathbf{4 c}$ crystal structure (CIF)

\section{Author Information}

\section{Corresponding Author}

Mamoru Tobisu - Department of Applied Chemistry, Graduate School of Engineering, Osaka University, Suita, Osaka 565-0871, Japan; Innovative Catalysis Science Division, Institute for Open and Transdisciplinary Research Initiatives (OTRI), Osaka University; http://orcid.org/0000-0002-8415-2225; E-mail: tobisu@chem.eng.osaka-u.ac.jp

\section{Authors}

Takuya Kodama - Department of Applied Chemistry, Graduate School of Engineering, Osaka University, Suita, Osaka 565-0871, Japan; Innovative Catalysis Science Division, Institute for Open and Transdisciplinary Research Initiatives (OTRI), Osaka University; http://orcid.org/0000-0001-8275-2393

Yuki Kawashima - Department of Applied Chemistry, Graduate School of Engineering, Osaka University, Suita, Osaka 565-0871, Japan

Zhirong Deng - Department of Applied Chemistry, Graduate School of Engineering, Osaka University, Suita, Osaka 565-0871, Japan

\section{Notes}

The authors declare no competing financial interest.

\section{Acknowledgement}


This work was supported by a Grant-in-Aid for Early-Career Scientists (19K15564) from MEXT, Japan. We also wish to thank the Instrumental Analysis Center, Graduate School of Engineering, Osaka University, for their assistance with the HRMS.

\section{References}

(1) (a) Dauben, H. J. Jr.; Ringold, H. J. SYNTHESIS OF TROPONE. J. Am. Chem. Soc. 1951, 73, 876; (b) Nozoe, T.; Mukai, T.; Takase, K.; Nagase, T. Tropone and Its Derivatives. VII. On Tropone (Cycloheptatrienone). Proc. Jpn. Acad. 1952, 28, 477-482.

(2) Doering, W. E.; Detert, F. L. CYCLOHEPTATRIENYLIUM OXIDE. J. Am. Chem. Soc. 1951, 73, 876-877.

(3) (a) Giacomo, A. D.; Smyth, C. P. The Dipole Moments and Molecular Structures of Cycloheptatrienone and Three Tetracyclones. J. Am. Chem. Soc. 1952, 74, 4411-4413; (b) Kurita, Y.; Seto, S.; Nozoe, T.; Kubo, M. Dipole Moments of Tropone, 2-Phenyltropone, Tropolone Methyl Ether and their Derivatives. Bull. Chem. Soc. Jpn. 1953, 26, 272-275.

(4) Selected reviews on tropones, see: (a) Pauson, P. L.Tropones and Tropolones. Chem. Rev. 1955, 55, 9-136; (b) Nozoe, T. RECENT ADVANCES IN THE CHEMISTRY OF TROPONOIDS AND RELATED COMPOUNDS IN JAPAN. Pure. Appl. Chem. 1971, 28, 239-280; (c) Pietra, F. Seven-membered conjugated carbo- and heterocyclic compounds and their homoconjugated analogs and metal complexes. Synthesis, biosynthesis, structure, and reactivity. Chem. Rev. 1973, 73, 293-364; (d) Pietra, F. Revival of troponoid chemistry. Acc. Chem. Res. 1979, 12, 132-138; (e) Ito, S.; Fujise, Y. Thermal Cycloaddition Reaction of Tropylium Compounds. J. Synth. Org. Chem. Jpn. 1977, 35, 176-187; (f) Fischer, G. Tropones, Tropolones, and Tropylium Salts with Fused Heterocyclic Rings: Part 1: Synthesis. Adv. Heterocycl. Chem. 1995, 64, 81157; (g) Fischer, G. Tropones, Tropolones, and Tropylium Salts with Fused Heterocyclic Rings: Part 2: Structure, Reactivity, and Application. Adv. Heterocycl. Chem. 1996, 66, 285-403; Zhao, J. Plant Troponoids: Chemistry, Biological Activity, and Biosynthesis. Curr. Med. Chem. 2007, 14, 2597-2621; (h) Abe, N. The Chemistry of Troponoids and Related Compounds. Oleoscience 2007, 11, 479-486; (i) Bentley, R. A fresh look at natural tropolonoid. Nat. Prod. Rep. 2008, 25, 118-138; (j) Dastan, A.; Kilic, H.; Saracoglu, N. One hundred years of benzotropone chemistry. Beilstein J. Org. Chem. 2018, 14, 1120-1180

(5) (a) Aihara J. A new definition of Dewar-type resonance energies. J. Am. Chem. Soc. 1976, 98, 2750-2758; (b) Kurihara, T.; Ishikawa, Sumio; Nozoe, T.; Aihara, J. Stability and Resonance Energy of Troponoid Compounds. Bull. Chem. Soc. Jpn. 1999, 72, 2111-2114; (c) Najafian, K.; Schleyer, P. v. R.; Tidwell, T. T. Aromaticity and antiaromaticity in fulvenes, ketocyclopolyenes, fulvenones, and diazocyclopolyenes. Org. Biomol. Chem. 2003, 1, 3410-3417; (d) Feixas, F.; Matito, E.; Poater, J.; Solá, M. On the performance of some aromaticity indices: a critical assessment using a test set. J. Comput. Chem. 2008, 29, 1543-1554; (e) Noorizadeh, S.; Shakerzadeh, E. Shannon entropy as a new measure of aromaticity, Shannon aromaticity. Phys. Chem. Chem. Phys. 2010, 12, 4742-4749.

(6) (a) Bertelli D. J. and Andrews Jr. G. T. Synthesis and study of pseudoaromatic compounds. IX. A reevaluation of the question of aromatic character in tropones based on data derived from dipole moment measurements and CNDO/2[complete neglect of differential overlap/2] calculations. J. Am. Chem. Soc. 1969, 91, 5280-5286; (b) Veracini, C. A.; Pietra, F. Molecular structure of tropone from its ${ }^{1} \mathrm{H}$ nuclear magnetic resonance spectrum in 
a nematic solvent. J. Chem. Soc., Chem. Commun. 1972, 8, 1262-1263; (c) Minato, S.; Yamabe, S.; Hasegawa, T.; Machiguchi, T. Tropothione versus tropone: A comparison of the charge separation in the ground state. Tetrahedron 1995, 51, 2507-2514; (d) Hasegawa, T.; Machiguchi, T.; Yamabe, S. Minato, T. Infrared spectroscopy of tropothione. J. Mol. Struct. (Theochem) 1997, 418, 221-229.

(7) (a) Schleyer, P. v. R.; Maerker, C.; Dransfeld, A.; Jiao H.; Hommes, N. J. R. v. E. Nucleus-Independent Chemical Shifts: A Simple and Efficient Aromaticity Probe. J. Am. Chem. Soc. 1996, 118, 6317-6318; (b) Schleyer, P. v. R.; Jiao H.; Hommes, N. J. R. v. E.; Malkin, V. G.; Malkina, O. L. An Evaluation of the Aromaticity of Inorganic Rings: Refined Evidence from Magnetic Properties. J. Am. Chem. Soc. 1997, 119, 12669-12670; (c) Chen. Z.; Wannere, C.S.; Corminboeuf, C.; Puchta, R.; Schleyer, P. v. R. NucleusIndependent Chemical Shifts (NICS) as an Aromaticity Criterion. Chem Rev. 2005, 105, 3842-3888.

(8) Havenith, R. W. A.; Fowler, P. W.; Steiner, E. Substituent effects on induced current densities in penta- and heptafulvenes. J. Chem. Soc., Perkin Trans. 2, 2002, 502-507.

(9) (a) Harmon, K. M., Harmon, A. B., Alderman, S. D., Gebauer, P. A.; Hesse, L. L. Iodine-cycloheptatriene system. J. Org. Chem. 1967, 32, 2012-2013; (b) Harmon, K. M., Harmon, A. B., Coburn, T. T.; Fisk, J. M. Carbonium ion salts. XI. Convenient preparations of hydroxytropenylium salts, ditropenyl ether, and tropone. J. Org. Chem. 1968, 33, 2567-2568.

(10)(a) Bertelli, D. J.; Andrews Jr., T. G.; Crews, P. O. Synthesis and study of pseudoaromatic compounds. X. A reevaluation of the question of aromatic character in tropone, tropolone, and substituted heptafulvenes based on the analysis of the nuclear magnetic resonance spectra of these and several related compounds. J. Am. Chem. Soc. 1969, 91, 5286-5296; (b) Ariafard, A.; Lin, Z. Theoretical studies on the protonation behavior of tropone and its metal complexes. J. Organomet. Chem. 2006, 691, 4545-4555.

(11)Jandl, C.; Pöthig, A. Hydroxytropylium chloride: the first crystal structure of an unfunctionalized hydroxytropylium ion. Acta Cryst. 2017, C73, 810-813.

(12)(a) Schaeppi, W. H.; Schmid, R. W.; Heilbronner, E.; Eschenmoser, A. Untersuchungen in der BenztropyliumReihe. I. Das 2', 3', 4', 4-Tetramethoxy-benztropylium-Kation. Helv. Chim. Acta 1955, 38, 1784-1890; (b) Kloster-Jensen, E.; Taröky, N.; Eschenmoser, A.; Heilbronner, E. Untersuchungen in der Benztropylium-Reihe. III. 2,7- Polymethylen-4,5-benztropone. Helv. Chim. Acta 1956, 39, 786-805; (c) Schmid, R. W.; KlosterJensen, E.; Kováts, E.; Heilbronner, E. Untersuchungen in der Benztropylium-Reihe. IV. Die Bildungsenthalpien des 2,7-Dimethyl-4,5-benztropons, des 2,7-Dodecamethylen-4,5-benztropons und des 2,7Pentamethylen-4,5-benztropons. Helv. Chim. Acta 1956, 39, 806-812; (d) Gäumann, T.; Schmid, R. W.; Heilbronner, E. Untersuchungen in der Benztropylium-Reihe V. Die Dipolmomente des 2,3-Benztropons, des 4,5-Benztropons und 2,7-disubstituierter 4,5-Benztropone. Helv. Chim. Acta 1956, 39, 1985-1993; (e) Schmid, R. W.; Heilbronner, E. Untersuchungen in der Benztropylium-Reihe. VI. Die polarographische Reduktion des 2,3-Benztropons, des 4,5-Benztropons und der 2,7-Polymethylen-4,5-benztropone. Helv. Chim. Acta 1957, 40, 950-957; (f) Rennhard, H. H.; Modica, G. D.; Simon, W.; Heilbronner, E.; Eschenmoser, A. Untersuchungen in der Benztropylium-Reihe. VII. 2,3-Benztropon und Benztropylium-Kation. Helv. Chim. Acta 1957, 40, $957-$ 968. (g) Meuche, D.; Strauss, H.; Heilbronner, E. Untersuchungen in der Benztropylium-Reihe. VIII. Das Säure-Basen-Gleichgewicht zwischen den Benzologen des Tropylium-Kations und ihren konjugaten Pseudobasen. Helv. Chim. Acta 1958, 41, 57-70; (h) Meuche, D.; Strauss, H.; Heilbronner, E. Untersuchungen 
in der Benztropylium - Reihe IX. Die Absorptions-Spektren der 2-Alkyl-4,5-benztropone, 2,7-Dialkyl-4,5benztropone und 5,7-Dialkyl-2,3-benztropone. Helv. Chim. Acta 1958, 41, 2220-2229; (i)Dipole Meuche, D.; Gäumann, T.; Heilbronner, E. Untersuchungen in der Benztropylium-Reihe X. Die Dipolmomente der 2,7Dialkyl-4,5-benztropone. Helv. Chim. Acta 1958, 41, 2230-2235; (j) Meuche, D.; Gäumann, T.; Heilbronner, E. Untersuchungen in der Benztropylium-Reihe XI Über den Einfluss von Alkylgruppen auf Spektrum und Basizität des Benztropylium-Kations. Helv. Chim. Acta 1959, 42, 452-460; (k) Naville, G.; Strauss H.; Heilbronner, E. Untersuchungen in der Benztropylium-Reihe XII. Absorptionsspektrum und Acidität benzologer Tropylium-Kationen. Helv. Chim. Acta 1960, 43, 1221-1243; (l) Naville, G.; Strauss H.; Heilbronner, E. Untersuchungen in der Benztropylium - Reihe XIII: Hückel-MO's benzologer TropyliumKationen. Helv. Chim. Acta 1960, 43, 1243-1254; (m) Götz, H.; Heilbronner E.; Katritzky, A. R.; Jones, R. A. Untersuchungen in der Benztropylium-Reihe. XIV. Identifizierung der Carbonylbande in den IR.-Spektren des Tropons und seiner Benzologen. Helv. Chim. Acta 1961, 44, 387-394.

(13)(a) Stiles, M.; Libbey, A. J. Tribenzotropone from a 1,3-Rearrangement. J. Org. Chem. 1957, 22, 1243-1246; (b) Buchanan, G. L.; Lockhart, D. R. 720. Tropolones. Part X. Synthesis and properties of 2,3-benzotropone. J. Chem. Soc. 1959, 3586-3594; (c) Shimanouchi, H.; Hata, T.; Sasada, Y. An x-ray determination of the conformation of dibenzo[b,f]tropone. Tetrahedron Lett. 1968, 9, 3573-3574; (d) Bertelli, D. J.; Gerig, J. T. C.; Herbelin, J. M. Synthesis and study of pseudo-aromatic compounds. VI. Synthesis of 6,7dihydrocyclohepta[de]naphthalene and a conformational analysis of 1,2-benzoheptafulvene. J. Am. Chem. Soc. 1968, 90, 107-113; (e) Hata, T.; Shimanouchi, H.; Sasada, Y. An x-ray determination of the structure of 4,5benzotropone. Tetrahedron Lett., 1969, 10, 753-754; (f) Ibata, K.; Hata, T.; Shimanouchi, H.; Sasada, Y. XRay determination of the conformations of 5-chloro-2,3-benzotropone and 5,7-dibromo-2,3-benzotropone. Chem. Comm. 1972, 339-340; (g) Ibata, K.; Shimanouchi, H.; Sasada, Y. THE X-RAY DETERMINATION OF THE CONFORMATIONS OF 2,7-DIMETHYL- AND 2,7-DIPHENYL-4,5-BENZOTROPONE. Chem. Lett. 1973, 2, 269-272; (h) Olah, G. A.; Liang, G. Stable carbocations. CLXXXI. Dihydrodibenzotropylium and dibenzotropylium ions. Neighboring methyl, cyclopropyl, and phenyl substituent effects in geometrically constrained systems. J. Org. Chem. 1975, 40, 2108-2116; (i) Ibata, K.; Shimanouchi H.; Sasada, Y. Structural Chemistry of the Benzotropone System. IV. The Crystal and Molecular Structure of 2,7-Diphenyl-4,5benzotropone. Acta Cryst. 1977, B33, 1129-1138; (j) El-Fayoumy, M. A. G.; Bell, H. M.; Ogliaruso, M. A.; Arison, B. H. Mono- and bishomobenzotropones. 2. Preparation and nuclear magnetic resonance spectra of 1hydroxy-2,3-benzotropylium cation, 1-hydroxy-2,3-benzohomotropylium cation, 1-hydroxy-2,3benzobishomotropylium cation and their deuterated analogs. J. Org. Chem. 1981, 46, 1603-1606; (k) Experimental and computational studies of naphtho[2,3-c]tropone: a highly polarized novel troponid system. Tetrahedron Lett. 2001, 42, 7295-7297; (1) $\pi$-Extended $o$-quinoidal tropone derivatives: experimental and theoretical studies of naphtho[2,3-c]tropone and anthro[2,3-c]tropone. Org. Biomol. Chem. 2004, 2, 10441050; (m) Kudoh, M.; Satoh, T.; Ikeda, H.; Nakazawa, T.; Miyashi, T.; Katagiri, S.; Sudoh, S. Experimental and Computational Studies on the Dipole Moments of Annulated-Tropones and 1,4-Polyacenequinones. Bull. Chem. Soc. Jpn. 2009, 82, 70-75. 
(14)(a) Kodama, T. Kawashima, Y.; Deng Z.; Tobisu, M. Synthesis of 4,5-Benzotropone $\pi$-Complexes of Iron, Rhodium and Iridium and Their Potential Use in Catalytic Borrowing Hydrogen Reactions. ChemRxiv, Submitted.

(15)(a) Thiele, J.; Schneider, J. Über Condensationsproducte des o-Phtalaldehyds. Justu Liebigs Ann. Chem. 1909, 369, 287-299; (b) Thiele, J.; Weitz, E. Über Kondensationsprodukte des o-Phtalaldehyds. Justus Liebigs Ann. Chem., 1910, 377, 1-22.

(16)(a) Krygowski, T. M.; Cyrański, M. K. Separation of the energetic and geometric contributions to the aromaticity of $\pi$-electron carbocyclics. Tetrahedron. 1996, 52, 1713-1419; (b) Krygowski, T. M.; Cyrański, M. K. Structural Aspects of Aromaticity. Chem. Rev. 2001, 101, 1385-1419.

(17)Geuenich, D.; Hess, K.; Köhler, F.; Herges, R. Anisotropy of the Induced Current Density (ACID), a General Method To Quantify and Visualize Electronic Delocalization. Chem. Rev. 2005, 105, 3758-3772. 